Brit. J. industr. Med., 1957, 14, 1

\title{
THE DANGER OF DERMATOSES DUE TO COLD-SETTING ETHOXYLINE RESINS (EPOXIDE RESINS)
}

\author{
BY \\ E. GRANDJEAN \\ From the Institute of Hygiene and Industrial Physiology of the Swiss Federal School of Technology, Zurich
}

(RECEIVED FOR PUBLICATION JULY 24, 1956)

A new group of synthetic resins (the ethoxyline or epoxide resins) has been widely accepted in industry during the last few years. These resins, thanks to their novel properties as adhesives and casting resins, are used in the modern manufacture of various kinds of apparatus, of electrical equipment, of automobiles, and of aircraft. They are usually supplied in the form of two reactive components, resin and hardener.

The cold-setting casting resins occupy a special position among the ethoxyline resins, most of which are aliphatic-aromatic polyethers containing hydroxyl and terminal epoxy groups. The highly reactive hardeners employed are usually polyamines. Mixtures of these two are capable of transformation at room temperature into solid, infusible substances. In practice, the ethoxyline resin is mixed with the polyamine hardener in the ratio of about $10: 1$ immediately before use and then applied to the desired point of the material by casting or brushing or injecting.

The ethoxyline resins were introduced under the general term "epoxide or epoxy" resins, being offered under the trademarks "epon" or "araldite" casting resin. As is well known, both manufacturers and users of lacquers are familiar with the handling of dangerous substances and apply comprehensive protective measures; as a result few or no dermatoses have appeared in lacquer factories till now. Dermatoses were reported in the U.S.A. too after these products had been found useful in various industries as adhesives and casting resins.

The introduction of ethoxyline resins into works hitherto unfamiliar with chemical processes brought the operatives into contact for the first time with substances which carried an unknown risk to the skin. Therefore, the first extensive " epidemics" of skin eruptions appeared mainly in such " nonchemical " factories.

The first observations of skin irritation during work with such resins were reported by Pletscher,
Schuppli, and Reipert (1954). Six out of 20 operatives working with " araldite" casting resin D suffered from severe eczema, eight exhibited only slight, temporary epidermal irritation, and the rest remained free of symptoms. Since the epidermal symptoms were apparently of an allergic nature, the 20 operatives were patch-tested for epidermal sensitivity to " araldite" casting resin D, hardener 951 (triethylenetetramine), and various other substances. These tests showed that out of the 14 workmen suffering from epidermal reactions, four were hypersensitive to " araldite" casting resin D, two to hardener 951 , and three to both substances. The men free from symptoms exhibited no hypersensitivity. On the basis of their observations, the authors concluded that contact with " araldite" casting resin D and hardener 951 can lead to allergic epidermal eczema. The present paper describes our investigations in 11 factories in four European countries (mainly in electrical engineering) using these substances.

\section{Atmospheric Pollution by Vapours of Triethylene- tetramine}

Araldite resins are practically non-volatile and are therefore only present in traces in the surrounding atmosphere. We therefore determined the concentration of triethylenetetramine (T.E.T. = hardener 951) in the atmosphere as a measure of the degree of pollution of the air at the work bench.

Method.-The air to be analysed was passed through two absorption tubes filled with glass beads. For each analysis, portions of up to 160 litres of air were passed over a period of several hours. We employed either $0.1 \mathrm{NHCl}$ or cation- and $\mathrm{CO}_{2}$-free distilled water as the absorbing agent. The absorbed T.E.T. was then determined quantitatively in the laboratory with the amine test reaction using 1 : 2-naphthoquinone-4-sulphonic acid according to the method of Englis and Fiess (1944).

Experiments.-In a first series of experiments, tin lids were filled at short intervals during eight hours with a mixture of araldite casting resin D/T.E.T. in an unventi- 
lated room of $16.5 \mathrm{c} . \mathrm{m}$. volume. On a model work bench, the quantities of araldite casting resin D thus cast per day amounted to 1,800 to $4,200 \mathrm{~g}$. and the total surface cast per day to about 5,000 to $15,000 \mathrm{~cm}^{2}$. This exceeded the amount usually employed per day on one factory work bench.

The T.E.T. concentration measured at head level at our model work bench varied between 0.31 and $0.59 \mu \mathrm{g}$./1. air. We tried in a similar manner to measure the T.E.T. concentration at head level above two work benches in a condenser factory in which condensers were continuously cast. The total surface of " araldite " casting resin $D$ cast daily varied between 1,500 and $3,500 \mathrm{~cm}^{2}$, and the quantities processed daily per operative between 3,400 and $3,600 \mathrm{~g}$. In spite of the fact that more than 100 litres of air were drawn through the absorption tubes for each analysis, the T.E.T. concentrations measured never exceeded the lower limit of analysis of about $0.15 \mu \mathrm{g}$./1. air. We concluded that at a normal work bench the average concentration of T.E.T. vapour at head level is below the limit of measurement of $0 \cdot 15 \mu \mathrm{g} . / 1$. air.

\section{Working Conditions at Work Benches in 11 Factories Studied}

The nature of the operations in these factories was as shown in Table 1. Whereas the ratio of resin to

TABLE 1

THE APPLICATIONS OF ARALDITE CASTING RESIN D IN 11 FACTORIES INVESTIGATED

\begin{tabular}{|c|c|}
\hline No. and Description of Factory & $\begin{array}{l}\text { Particular Use of Araldite } \\
\text { Casting Resin D }\end{array}$ \\
\hline $\begin{array}{l}1 \text { (condenser factory) } \\
2 \text { (condenser factory) } \\
3 \text { (electrotechnical factory) } \\
4 \text { (electrical apparatus works) } \\
5 \text { (manufacture of telephones } \\
\text { and other electrical apparatus) } \\
6 \text { (telephone factory) } \\
7 \text { (electrical apparatus works) } \\
8 \text { (refrigerator factory) } \\
9 \text { (manufacture of telephones } \\
10 \text { and other electrical apparatus) } \\
11 \text { (manufactory) } \\
\text { and other electrical appliances) }\end{array}$ & $\begin{array}{l}\text { Sealing condensers } \\
\text { Sealing condensers } \\
\text { Sealing condensers } \\
\text { Coil assembly } \\
\text { Sealing condensers } \\
\text { Casting switch boxes and } \\
\text { contact connexions } \\
\text { Sealing condensers } \\
\text { Casting coils and lead couplings } \\
\text { Coil assembly } \\
\text { Sealing condensers } \\
\text { Sealing condensers } \\
\text { Coil assembly } \\
\text { Refrigerator assembly } \\
\text { Sealing condensers } \\
\text { Sealing cable ends } \\
\text { Sealing condensers }\end{array}$ \\
\hline
\end{tabular}

hardener was in all factories 10 to 1 (in some cases quartz, slate, or porcelain was added to the resin), the manner of mixing varied from automatic methods and vibromixers to manual mixing with spatulae.

The modes of applying the resin vary widely, e.g., manual casting (for large condensers), mechanical casting (for small condensers), manual application (in assembly of coils in switch boards) with immediate removal of exuded excess or later tooled removal after setting, pouring of resin on to parts of a frame to be bonded (refrigerator assembly) with later removal of excess. Some factories had installed ventilator hoods over casting work benches.
On inspecting the techniques employed, the work benches were always found to be contaminated as well as tools, clothes, and the hands of the operatives. The containers for the resin are often very unsatisfactory and permit it to overflow on to the bench during pouring. The women wipe up the mess with their fingers. Stirrers, spatulae, brushes, and other implements with much adherent resin are laid on the benches. These and other causes increase the probability of skin contamination, which is further increased by the use of cleansing solvents (acetone, alcohol, butanone, trichloroethylene, and mixtures of aromatic hydrocarbons).

\section{Clinical Aspects of Epoxy-resin Dermatosis}

These have been variously described. Plüss (1954) and Pletscher et al. (1954) classify them as industrial eczemas, usually on the hands and forearms, with oedema of the face. Welcker (1955) considers the condition to be acute seborrhoeic eczema; Malten (personal communication) sees it as a progression from an initial patchy eczema to a later papular and vesicular eczema. Welfling (personal communication) speaks of a "dermite érythemateuse" or " dermite eczématiforme". Bory, Lecocq, and Negri (1955) saw 14 cases, some of erythema or urticaria, others of acute vesicular eczema with facial oedema.

Our observations in 11 factories permit the following description:-

The initial stage, lasting from one week to several months, is seen as erythematous itching patches, in the face alone in one in three cases, in the upper extremities in one in five cases, and in the face and upper extremities in one in three cases. Recovery may occur in two to three weeks with scaling. The precise nature of this stage is not understood, but the patches may be a primary irritation due to alkaline hardener or to an early manifestation of sensitization to resin. The effect may never proceed beyond this stage in some operatives, who need not, therefore, cease work, or the process of so-called "hardening" may become established (Schwartz, Tulipan, and Peck, 1947), when the operative becomes sensitized and the second stage appears when contact is resumed. It is characterized by a papulo-vesicular eruption; severe itching leads to scratching, and to the breakdown of vesicles with oozing (wet eczema). The sites of the eruption are as in the initial stage, and the eczematous patches may heal in a few weeks after scaling. Work must be discontinued if this stage is reached. Patch tests show sensitivity to resin in many cases, to hardeners in some and to both in many. Polyvalent sensitization may become established. Table 2 shows the incidence of slight or severe dermatoses 
TABLE 2

INVESTIGATIONS OF 11 FACTORIES USING ARALDITE CASTING RESIN D AND HARDENER 951

\begin{tabular}{|c|c|c|c|c|c|c|c|c|c|c|c|c|c|}
\hline Factory No. & 1 & 2 & 3 & 4 & 5 & 6 & 7 & 8 & 9 & 10 & 11 & Total & Average \\
\hline $\begin{array}{l}\text { Consumption of araldite casting resin } \\
\text { D/operative/year (kg.) }\end{array}$ & 381 & 92 & 28 & 62 & 20 & 187 & 100 & 86 & 162 & 31 & 29 & - & - \\
\hline $\begin{array}{l}\text { Total number of operatives handling } \\
\text { araldite casting resin } D \text { to March, } \\
1955^{*}\end{array}$ & 84 & 15 & 48 & 15 & 28 & 75 & 4 & 5 & 4 & 32 & 18 & 328 & - \\
\hline $\begin{array}{l}\text { Total number of dermatoses } \\
\% \text { of all dermatoses, based on total } \\
\text { number of operatives working with } \\
\text { araldite casting resin D }\end{array}$ & $\begin{array}{l}56 \\
67\end{array}$ & 60 & $\begin{array}{l}12 \\
25\end{array}$ & $\begin{array}{r}7 \\
47\end{array}$ & $\begin{array}{l}17 \\
61\end{array}$ & $\begin{array}{l}53 \\
70\end{array}$ & 75 & $\begin{array}{r}1 \\
20\end{array}$ & $\begin{array}{r}1 \\
25\end{array}$ & $\begin{array}{l}2 \\
6\end{array}$ & $\begin{array}{r}3 \\
17\end{array}$ & 164 & $\overline{43 \cdot 0}$ \\
\hline $\begin{array}{l}\% \text { of slight dermatoses based on total } \\
\text { number of operatives working with } \\
\text { araldite casting resin D }\end{array}$ & 31 & 13 & 8 & 20 & 29 & 29 & 50 & 20 & 25 & 6 & 0 & 一 & $21 \cdot 0$ \\
\hline $\begin{array}{l}\% \text { of severe dermatoses based on total } \\
\text { number of operatives working with } \\
\text { araldite casting resin D (off work for } \\
\text { more than three days or permanently) }\end{array}$ & 36 & 47 & 17 & 27 & 32 & 41 & 25 & 0 & 0 & 0 & 17 & - & $22 \cdot 0$ \\
\hline
\end{tabular}

* The number of operatives who had worked with " araldite" casting resin D since its introduction could not be established with certainty in all factories; they have therefore in part been estimated by the works management.

Protective measures ranged from poor to very good.

in the $\mathbf{1 1}$ factories studied; these correspond closely to the nature of the protective measures used.

\section{The Causes of the Eruptions}

From the case histories and our own patch tests it was evident that the skin reactions follow contact with the liquid stage of the resin and hardener or with mixtures of these before setting is complete. This applies both to the stages of apparent direct irritation and of sensitization. A mean time of setting is about 48 hours, before which time contact with the material should be prevented. The set, hardened resin appears to be innocuous as far as skin reactions are concerned. The vapour pressures of the casting resin and of the hardener are so low that atmospheric concentrations are negligible in respect of the early and sensitization effects on the skin of the face, for example. We are of the opinion, therefore, that the problem is one of direct contact of the liquid materials with the skin, but we do not exclude the possibility that even the low concentrations of resin or hardener vapours may be sufficient to induce a recurrence in a sensitized subject.

\section{Preventive Measures}

From the nature of the operations in which the liquid materials are used, it is apparent that protection of the worker must be instituted so as to obviate the practices to which the worker himself is prone, e.g., wiping contaminations from the skin with rags impregnated with solvent and resin; wiping perspiration from the face or neck in hot weather with contaminated hands or rags; failure to wash the hands before necessary contacts with the thighs or buttocks.

We consider it necessary to outline in some detail the various aspects of protection, namely, $(a)$ instruction to workers and foremen; (b) action directed toward the hazard of the contaminated work bench, cleaning rags and solvents, containers; (c) removal of vapours by exhaust ventilation; $(d)$ protection of the individual skin; $(e)$ care of the skin; $(f)$ medical measures.

(a) The individual worker should be trained by an experienced foreman in how to use these resins and hardeners and taught that traces of casting resin on common articles (tables, chairs, shoes, clothes, machines, buttons, door handles, pencils, etc.) may be the source of skin inflammations. Having regard to the very high incidence of lost time which may result from bad working practice, it is suggested that incentives to care and cleanliness in working should be considered.

(b) The work bench and the surrounding area should be covered by a removable layer of strong paper on to which the casting resin may drip to prevent permanent contamination. The soiled, blotched paper could be removed twice daily and destroyed. The degree of soiling of the paper offers a means of assessing the care and efficiency of the workers. Fresh cleaning rags should be supplied daily and used only for occasional cleansing of apparatus, machines, and containers. Contaminated rags should be handled with gloves. The use of solvents for removing spots of resin on the skin or nails should be abandoned. When apparatus is cleaned with solvents, the worker should wear gloves, e.g., of polythene. Ketonic solvents are preferable. Chlorinated and hydrocarbon solvents should be banned. It is desirable that the mixing, distributing and, if possible, casting of the resin should be done with thick, cardboard, spouted containers which can later be discarded, thus avoiding cleansing operations.

(c) Although good ventilation and local exhaust at the working point are desirable, especially where sensitized workers are concerned, they are secondary, in general, to the need to prevent direct contact of 
the skin with the liquid materials, resin, or hardener.

(d) The well-known objection to gloves in work of this kind can to some extent be overcome by the use of soft leather gloves with knitted backs or, alternatively, thin cotton gloves under polythene, since the cured resin mixture does not adhere to the latter. In some diluent operations it may be desirable to use soft leather finger stalls with knitted backs. Whatever method is chosen washing must be thorough and the appliance kept clean and dry ready for use. Barrier creams ("sternocleanse" No. 2, "kerodex" No. 1 or No. 7, "kerodex" BQN 1, " defensyl W", " fissan" protective ointment) have their place in protection of the skin in this work, especially for the face. Less effective than gloves they nevertheless do offer a certain amount of protection. The use of white overalls and plastic cuffs for the forearms offers additional protection, provided they are washed at least twice weekly, or at once if contamination is visible.

(e) For operations of this kind it is desirable to install facilities for washing in the working room, with not too hard brushes and paper towels and barrier creams provided. Malten recommends mild soaps or emulsions or ordinary " sunlight" household soap. In France acid soaps are used. Finger nails should be kept short and clean. After the day's work washing should be followed by inunction of the hands with a mild fatty ointment, e.g., lanoline and vaseline, $1: 1$. The claim of some manufacturers that washing facilities in the workroom have an adverse effect on the processes is not considered justified, since the atmospheric moisture is mainly attributable to the presence of human subjects (perspiration and expiration). The time required for efficient washing and skin protection should be determined and made an official allowance.

( $f$ ) Pre-employment medical examination should eliminate allergic subjects from work in these processes. If the initial stage of skin irritation develops an attempt can be made to prevent sensitization by reducing the daily period at the bench when the casting resin is used and by intensifying the measures to prevent mechanical irritations and maintained contact with the potential allergens. If such measures fail and sensitization becomes established, further work and contact with the casting resin and hardener must cease. Eruptions should, on the whole, be treated by a dermatologist, only the mildest therapeutic agents being employed in the early stages in the factory.

\section{Summary}

Synthetic resins of the ethoxyline group ("araldite" casting resin) have caused many dermatoses. In 11 factories making electrical equipment, the work benches and the workers using "araldite" casting resin D were investigated. One hundred and sixtyfour out of 328 workers showed dermatoses which could be classified as skin irritations (erythematous itching patches) and severe allergic eczemas caused by direct contact either with the liquid " araldite resin D" or with hardener 951 (triethylenetetramine), or with a not already polymerized mixture of both.

The preventive measures are discussed in detail. These include $(a)$ instruction of workers and foremen; (b) action directed towards eliminating the hazard of the contaminated work bench, cleaning rags, solvents, and containers; $(c)$ removal of vapours by exhaust ventilation; $(d)$ individual protection of the skin; $(e)$ care of the skin; and $(f)$ medical measures.

\section{REFERENCES}

Bory, R., Lecocq, J., and Negri, R. (1955). Symposium sur les dermatoses professionelles-Suppl. to Arch. Mal. prof., 16, p. $\mathbf{S} 102$.

Englis, D. T., and Fiess, H. A. (1944). Industr. Engng Chem., 36, 604. Malten, $\mathbf{K}$. $\overrightarrow{\mathbf{F}}$. Personal communication (Amsterdam, Holland). Pletscher, A., Schuppli, R., and Reipert, R. (1954). Z. Unfallmed. Berufskr., 47, 163.

Plüss, J. (1954)., Ibid., 47, 83.

Schwartz, L., Tulipan, L., and Peck, S. M. (1947). Occupational

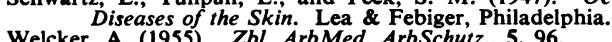

Welfling, A. (1955). Z Personal. ArbMed. ArbSchutz., 5, 96. France). 